\title{
Foreword by Linda L. Putnam
}

The research on gender and negotiation encompasses an interdisciplinary group of widely diverse, sophisticated scholars. This Handbook pays tribute to the scope, breadth, and depth of this work through treating gender not simply as a variable, but as a complex construct situated in contextual/situational parameters, dynamic processes, and paradoxical developments. This volume broadens the scope of this concept through examining the role of gender in everyday negotiations as well as workplace arrangements. In particular, chapters in this volume focus on negotiation in spousal-partner relations, work-life accommodations, and friendship activities. The conceptual developments in this volume underscore the breadth of this topic through exploring gender stereotypes, role congruity, role salience, expectancy theory, institutional systems, second generation gendered issues, and discursively enacted gender relationships. The depth of the gender-negotiation work surfaces in teasing out research findings, uncovering gaps, and aligning multiple bodies of literature.

In doing so, this Handbook offers a comprehensive research agenda for future studies as well as pragmatic suggestions for training women negotiators. Through examining the gaps in different paradigms, each chapter includes pivotal questions and important issues that shape a research agenda. This volume also highlights ways that women can recognize gender stereotypes, enhance self-work, and manage the tensions between agentic and communal behaviors. In addition, this book reveals three advances that serve as the building blocks for future work on gender and negotiation: (1) adopting a situational/contextual stance; (2) emphasizing dynamic processes; and (3) embracing the paradoxes that underlie both gender and negotiation. These topics are fundamental to the complexity of the gender-negotiation relationship.

\section{SITUATIONAL/CONTEXTUAL FEATURES}

Each chapter in this volume attests to the pivotal role of situation and context factors in accounting for gender differences. Research findings consistently show that detrimental stereotypes matter less when women are experienced bargainers, frame negotiation as asking, and treat it as a learning tool. Developing programmatic ways to feature situational and contextual parameters can help women strengthen their position in negotiation.

I first became interested in gender and negotiation in the early 1980s. One of my initial lab projects focused on sex differences in negotiation interaction and revealed the complexity of gender and role salience (Putnam and Jones, 1982). In this study, 
we discovered that same-sex dyads employed attacking statements while mixed-sex bargainers used more self-supporting arguments. However, when we moved away from frequency counts to examine sequential patterns of talk, these gender differences disappeared. As Stuhlmacher and Zervos suggest in their chapter in this volume, gender is a multifaceted concept embedded in roles, activities, and intersections of multiple identities. For example, in the Putnam and Jones (1982) study, assignments to labor and management roles exerted a much stronger influence on bargaining strategies and outcomes than did the gender of the negotiators. In effect, role complexity and dyadic composition serve as situational factors that mitigate gender salience.

This study, as well as other chapters in this volume (e.g., ones that highlight ethical norms linked to social groups, power in dyadic composition, and second generation gender issues), underscore the importance of holding gender and negotiation together as one intermingled construct rather than treating them as distinct phenomena. To hold them together, researchers need to explore how men and women do gender and negotiation (West and Fenstermaker, 1995); that is, how do they draw on meanings and practices grounded in gender-related situational and institutional circumstances that interface with negotiation processes? In effect, bargainers enact both gender and negotiation within particular contexts, such as spousal relationships, work-life interactions, friendships, and cross-cultural arenas. Comparisons across these contexts can reveal valuable insights as to the most pivotal situational features involved in doing both gender and negotiation.

\section{DYNAMIC PROCESSES}

To hold gender and negotiation together, researchers need to privilege the adaptive, responsive, and fluid aspects of bargaining. A number of chapters in this volume highlight gender performances through examining micro and macro bargaining tactics, responses to partners, escalation and de-escalation, moves and turns, and persistence in negotiation over time. Indeed, as several chapters in this volume suggest (i.e., Kulik, Sinha and Olekalns, Liu and Ren, Stuhlmacher and Zervos), the dynamic nature of gender (e.g., shifts in gender salience and responses to power moves) may account for the disparate findings in past sex differences research. Developing patterns of resilience and ways to recover from unexpected negative interactions in negotiation entails a dynamic process linked to gender performances (i.e., Olekalns and Kennedy, this volume).

Deciphering dynamic processes is one practice that seems missing from gender training, that is, practitioners need to teach women how to analyze and intervene in the ongoing negotiation process. This recommendation centers on helping them develop skills in reframing issues, asking circular questioning, fostering problem solving, expressing curiosity, and de-escalating conflict (Kolb and Porter, 2015; Kolb and Williams, 2003). Thus, training needs to move beyond analogic reasoning to focus on performances that can potentially alter gender triggers. In particular, 
women negotiators need to use humor, irony, ambivalence, and ambiguity to redirect the negotiation process, manage gender salience, and move talk from micro to macro levels of interaction. Sensitivity to the bargaining process centers on treating negotiation as an improvisational dance rather than as a transaction (Adair and Brett, 2005; McGinn and Keros, 2003).

\section{EMBRACING THE GENDER/NEGOTIATION PARADOX}

In addition to dynamic processes, researchers and practitioners can hold gender and negotiation together through focusing on the paradoxes that surface from gender binaries and the oppositions that underlie negotiation. Paradoxes stem from mutually exclusive opposites or contradictions that persist over time, become difficult to navigate, and often seem irrational or absurd (Lewis, 2000). Several chapters in this volume illustrate paradoxical features of the gender binary; namely, whether women should be agentic, assertive, self-oriented, and competitive (i.e., masculine stereotype) or behave in a more communal, friendly, other-oriented, and cooperative way (i.e., feminine stereotype). As Kulik et al. (this volume) point out, gender stereotypes set up either-or expectations for appropriate behaviors, ones that often become embedded in organizational structures. As they note, these expectations act as self-fulfilling prophecies that create vicious cycles in which the actions of women serve as proof of their deficiencies as negotiators. Thus, if women internalize gender stereotypes, they are less able to engage in agentic behaviors necessary for effective negotiation (Kulik et al., this volume); yet, if they adopt agentic styles, partners often respond with rejection (Kray and Kennedy, 2017).

The recommendations for managing this paradox include raising awareness of gender stereotypes, developing a personal style that includes both agentic and communal behaviors, and situating feminine behaviors as fundamental to effective negotiation (e.g., good listening, politeness, encouraging participation). These bothand approaches help women negotiators find the right balance between competition/ cooperation, instrumental/relational, economic/social, and agentic/communal (Kulik et al., this volume). Yet the exact nature and path to balance is tricky. Similar to standing on a tightrope, balance can easily swing to one side or the other of the poles and consequently, fuel vicious cycles (Cunha and Putnam, 2019).

Another way to manage paradox goes beyond balance to focus on continually connecting the opposites. For example, Putnam et al. (2016) recommend using humor, irony, and ambiguity to connect and transcend paradoxes. These approaches are similar to circumventing tensions and redirecting actions through moves and turns (Kolb and Porter, 2015) or reframing issues to reconcile agentic values with communal behaviors (Zheng et al., 2018). Yet they draw on alternative discourses to shift gender salience, as evident when women middle managers used humor to invoke multiple identities that navigated female leadership paradoxes through invoking multiple identities (Martin, 2004). 
Negotiation is also rooted in binaries, as opposites that surface in the dual concern model of self-versus-other (Pruitt, 1981), the interdependence between cooperation and competition (Lewicki et al., 2010), the necessity of enacting integrative and distributive processes (Walton and McKersie, 1965), and the simultaneity of trust and distrust (Lewicki et al., 2010). Thus, in many ways, both gender and negotiation evoke opposites that need to be held together rather than cast in either-or relationships.

Co-mingling both gender and negotiation provides an opportunity to rethink research designs, incorporate complexity, and examine how negotiators live out paradoxes. On the research level, scholars could develop theories and designs based on gender and negotiation as simultaneously intermingling opposites, for example, enacting both agentic and communal behaviors as part of revealing and concealing information in negotiation. Researchers could also focus on shifts between integrative and distributive negotiation as tensions that interface with gender salience (e.g., evoking multiple identities). The struggle between instrumental and relational goals in gender stereotypes also typifies tensions between self and other in negotiation orientations (Pruitt, 1981) and autonomy-connection in conflict interactions (Mayer, 2015). In effect, tensions and paradox form the lifeblood of performing both gender and negotiation and embracing their dual presence could produce alternative ways of conducting research and enacting practice.

To explore the interplay of opposites in gender and negotiation, both scholars and practitioners need to understand paradox. In particular, paradoxes emerge through ways that opposites have the potential to impose on and entrap each other. Thus, researchers need to explore the ways that interlocked relationships develop through connecting gender and negotiation. Several conflict scholars, while not focusing on gender per se, illustrate how to hold oppositional tensions in play. For example, Collier (2009) investigated how Protestant and Catholic participants in Belfast, Northern Ireland, enacted their opposing religious identities as interdependent with a new intergroup affiliation. By challenging the "us" versus "them" divide, she uncovered how negotiation paradoxically minimized violence between the two religious groups while affirming their opposing intra-group identities. Similarly, rather than relying on historically-defined ethnic identities, Jones and Bodtker (1998) studied how educators navigated the paradoxes of power (both gaining and losing power) between the US and South Africa through embracing the interplay of opposites. Paradox also surfaced in Donohue's (2001) relational model of negotiation that focused on embracing both cooperation and competition through juxtaposing high and low interdependence and high and low affiliations. As these examples illustrate, the key to holding opposites together is to be aware of paradoxical tensions, keep them in play, and use them to generate new spaces of action.

Another example centers on gender and compensation, but not negotiation. Specifically, meritocracy as a system for rewarding employees often leads to the opposite of what it intends; that is, evaluation systems grounded in merit often favored men over equally qualified women who had identical performance scores, jobs, and work units (Castilla and Benard, 2010). Although originally cast as a fair, unbiased, 
and objective system, the practice of distributing rewards based on merit triggered gender stereotypes through blocking the awareness of potential prejudice. In this case, the struggle of opposites, such as equity-inequity, objective-subjective, served as warning signs or triggers of potential bias. Ironically, using systems grounded in terms like managerial discretion raised awareness of possible discrimination in performance evaluations (i.e., playing out bias-unbiased) and led to decisions that compensated women fairly. In essence, developing a sensitivity to the dual presence of opposites provides a way of connecting them and holding them together to reframe and create new spaces for them. Loss of awareness of oppositional tensions often inadvertently triggers gender stereotypes and bias.

\section{CONCLUDING COMMENTS}

Overall, this volume enters the market at a time when scholars are searching for alternative ways to examine the complexities of gender and negotiation. As such, it adds breadth and depth to past research and sets forth agendas for future investigations. Specifically, it highlights situational factors linked to gender salience in multiple contexts and institutional constraints. It underscores the importance of focusing on the dynamic processes of bargaining and connecting gender and negotiation as interlocked performances. In this way, enacting negotiation becomes isomorphic with the doing of gender and vice versa. Additionally, it acknowledges the paradoxes that stem from gender binaries and identifies both-and options for navigating them.

Future studies, however, could do more to connect gender binaries with oppositional struggles inherent in negotiation. In particular, scholars need to embrace, connect, and intermingle opposites through weaving together gender and negotiation in research designs. Developing sensitivities to ironies and paradoxes is pivotal to uncovering the complexities in gender-negotiation research as well as to training women negotiators to manage oppositional tensions effectively.

\section{REFERENCES}

Adair, W. and Brett, J. (2005). The negotiation dance: Time, culture and behavioral sequences in negotiation. Organizational Science, 16, 33-51.

Castilla, E.J. and Benard, S. (2010). The paradox of meritocracy in organizations. Administrative Science Quarterly, 55, 543-76.

Collier, M.J. (2009). Negotiating intercommunity and community group identity positions: Summary discourses from two Northern Ireland intercommunity groups. Negotiation and Conflict Management Research, 2, 285-306.

Cunha, M.P. and Putnam, L.L. (2019). Paradox theory and paradox of success. Strategic Organization, 17, 95-106.

Donohue, W.A. (2001). Resolving relational paradox: The language of conflict in relationships. In W.F. Eadie and P.E. Nelson (eds), The language of conflict and resolution (pp. 21-46). Thousand Oaks, CA: Sage Publications. 
Jones, T.S. and Bodtker, A. (1998). A dialectical analysis of a social justice process: International collaboration in South Africa. Journal of Applied Communication Research, 26, 357-73.

Kolb, D.M. and Porter, J.L. (2015). Negotiating at work: Turn small wins into big gains. San Francisco, CA: Jossey-Bass.

Kolb, D.M. and Williams, J. (2003). Everyday negotiation: Navigating the hidden agendas in bargaining. San Francisco, CA: Jossey-Bass.

Kray, L.J. and Kennedy, J.A. (2017). Changing the narrative: Women as negotiators and leaders. California Management Review, 60, 70-87.

Lewicki, R.J., Saunders, D.M. and Barry, B. (2010). Essentials of negotiation (5th edn). New York: McGraw-Hill.

Lewis, M.W. (2000). Exploring paradox: Toward a more comprehensive guide. Academy of Management Review, 25, 760-76.

Martin, D.M. (2004). Humor in middle management: Women negotiating the paradoxes of organizational life. Journal of Applied Communication Research, 32, 147-70.

Mayer, B. (2015). The conflict paradox: Seven dilemmas at the core of disputes. San Francisco, CA: Jossey-Bass.

McGinn, K.L. and Keros, A.T. (2003). It takes two: Improvisations in negotiation. Administrative Science Quarterly, 47, 442-73.

Pruitt, D.G. (1981). Negotiation behavior. New York: Academic Press.

Putnam, L.L. and Jones, T.S. (1982). Reciprocity in negotiations: An analysis of bargaining interaction. Communication Monographs, 49, 171-91.

Putnam, L.L., Fairhurst, G.T. and Banghart, S. (2016). Contradictions, dialectics, and paradoxes in organizations: A constitutive approach. Academy of Management Annals, 10, $65-171$.

Walton, R.E. and McKersie, R.B. (1965). A behavioral theory of labor negotiations: An analysis of a social interaction system. New York: McGraw-Hill.

West, C. and Fenstermaker, S. (1995). Doing difference. Gender and Society, 9, 8-37.

Zheng, W., Kark, R. and Meister, A.L. (2018). Paradox versus dilemma mindset: A theory of how women leaders navigate the tensions between agency and communion. The Leadership Quarterly, 29, 584-96. 